\title{
Arthroscopic Suture Pull-Out Fixation of Displaced Tibial Spine Avulsion Fracture
}

\author{
Vivek Pandey, MS ${ }^{1}$ Suman CPS, MS ${ }^{1} \quad$ Kiran Acharya, MS ${ }^{1}$ Sharath K. Rao, MS ${ }^{1}$ \\ ${ }^{1}$ Department of Orthopaedics, Kasturba Medical College, Madhav \\ Nagar, Manipal, Udupi, Karnataka, India \\ Address for correspondence Vivek Pandey, MS, Department of \\ Orthopaedics, Kasturba Medical College, Manipal - Madhav Nagar, \\ J Knee Surg 2017;30:28-35. \\ Manipal, Udupi, Karnataka 576104, India \\ (e-mail: vivekortho@gmail.com).
}

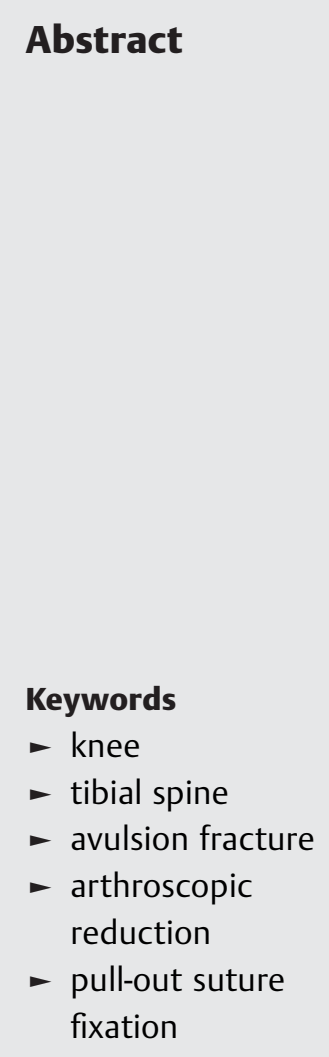

The aim of this study is to assess the clinical and radiological outcomes of arthroscopic reduction and fixation of tibial spine avulsion in patients with either open physis or closed physis, using high strength nonabsorbable sutures utilizing intravenous cannula needle as suture passer and retriever. Twenty-six patients of mean age 24.5 years were included in the study with a mean follow-up period of 31 months. Twelve patients had McKeever type III avulsion fracture and 14 had type IV. A follow-up analysis was performed using fracture union time, range of motion assessment, and Lysholm and IKDC (International Knee Documentation Committee) scores with instrumental (KT1000 arthrometer) laxity assessment. All avulsion fractures showed union at the end of a 3-month follow-up. Mean ( \pm standard deviation [SD]) postoperative Lysholm and IKDC subjective scores were 97.7 ( \pm 3.62, range, 89-100) and 95.55 ( $\pm 4.21,82.8-100)$, respectively. All patients were graded IKDC grade A except one with grade $B$. The Lysholm score of open physis group was better than the closed physis group (99.6 vs. 96.5, $p<0.03$ ), whereas IKDC scores of open versus closed physis group (both subjective and objective) and type III and IV McKeever groups did not reveal any statistical difference. KT-1000 assessment revealed mean ( \pm SD) anterior translation of the tibia as $0.85( \pm 0.9) \mathrm{mm}$. At the final follow-up, all patients achieved complete range of movement with no symptom of instability. Two patients underwent adhesiolysis for postoperative stiffness in their knee at 4 th month postoperatively. Arthroscopic suture pull-out fixation for type III and IV tibial spine avulsion results in excellent clinical and radiological outcomes in patient with open and closed physis without any significant complications. This is a prospective case series with level of evidence IV.
Tibial spine or anterior cruciate ligament (ACL) bony avulsion is, usually, a result of low-velocity injuries, such as fall from a bicycle or motorcycle and sports. ${ }^{1}$ It occurs when an axially loaded knee undergoes hyperextension, and the femur rotates externally. ${ }^{1}$ Meyers and McKeever classified avulsion fractures into three types. ${ }^{2}$ Type I as undisplaced, type II as partially displaced with intact posterior hinge, and type III as completely displaced. Zaricznyj proposed a fourth category (type IV) for comminuted avulsed fragment. ${ }^{3}$ Complications

received

May 28, 2015

accepted after revision

January 15, 2016

published online

March 10, 2016 of such untreated and displaced type III and IV avulsion fracture include nonunion or malunion, which can lead to significant disability in the form of flexion deformity, loss of extension, or instability. ${ }^{1,4,5}$ Hence, it is important to reduce accurately and fix type III and IV fractures and prevent such complications. Although Shelbourne et al recommend excision of displaced avulsed fragment and report good result, ${ }^{6}$ we believe that displaced tibial spine fractures are best treated with fixation because the native ACL has
Copyright $\odot 2017$ by Thieme Medical Publishers, Inc., 333 Seventh Avenue, New York, NY 10001, USA. Tel: +1(212) 584-4662.
DOI http://dx.doi.org/ 10.1055/s-0036-1579682. ISSN 1538-8506. 
mechanoreceptors for proprioception and neuromuscular control. ${ }^{7}$ Various techniques are described to achieve secure fixation of the avulsed fragment in type III and IV fractures which vary from Kirschner (K) wire, ${ }^{8}$ cancellous screws, ${ }^{9}$ Herbert screws, ${ }^{10}$ staples, $^{11}$ stainless steel wires, ${ }^{12}$ suture anchor, ${ }^{13}$ meniscal arrows, ${ }^{14}$ sutures $^{15-19}$ or combination, ${ }^{20}$ and so forth, using the mini-open or arthroscopic approach. ${ }^{21}$ In the last decade, arthroscopic pull-out suture technique seems to have gained popularity over another technique of fixation with reports of the excellent outcome. ${ }^{7,15,18,19}$ In the following prospective case series, we describe the clinical and radiological outcomes of arthroscopic fixation of ACL bony avulsion with suture pull-out technique using two high strength, nonabsorbable sutures and tying over a fixation button or bone bridge, utilizing universally available intravenous (I.V.) cannula needle as suture passer and retriever. We hypothesize that the clinical and radiological outcomes using this technique are comparable with recent literature.

\section{Materials and Methods}

In a prospective study with informed consent of all individual participants, 26 patients with acute type III or IV tibial spine avulsion who presented within 4 weeks of injury were included. Patients with both open and closed physis were included with age varying from 12 to 47 years. The diagnosis was confirmed by plain radiograph. Magnetic resonance imaging (MRI) was performed in all cases to assess the Meyer type of avulsion (III or IV) and associated intra-articular injuries. Computed tomography (CT) was performed in case of doubts regarding the McKeever type. Preoperative Lysholm and International Knee Documentation Committee (IKDC) scores were not obtained as they were all acute cases. After preoperative workup, patients underwent arthroscopic suture fixation of ACL bony avulsion by a single senior arthroscopic surgeon. All patients completed the minimum follow-up period of 24 months.

\section{Surgical Technique}

Under spinal or general anesthesia, diagnostic arthroscopy was performed through the standard anterolateral portal.
The joint and fracture bed was cleared of hematoma using continuous irrigation. Then, standard anteromedial portal was established. Chondral and meniscal injuries were assessed and managed as per established guidelines. The tibial spine avulsion was identified, and the type of fracture was confirmed by probing. In cases where the transverse intermeniscal ligament was entrapped between the bed and the avulsed fragment hampering the reduction, it was retracted out using a probe or preferably a traction suture. Next, 1-inch long skin incision was made parallel and medial to the tibial tuberosity. Remaining dissection was done with care to arrive up to the periosteum protecting the pes anserinus tendons and underlying medial collateral ligament. The tip of the ACL tibial guide (Conmed; Utika, New York) was subsequently placed via anteromedial (AM) portal in the medial-most edge and at the equator of avulsion crater. Next, a tibial tunnel was drilled using $1.8 \mathrm{~mm} \mathrm{~K}$-wire. Once K-wire tip was visualized emerging out at the crater edge, the tibial guide was disengaged and the K-wire was left in-situ. A similar step was performed for the lateral edge of the crater with another K-wire keeping $1 \mathrm{~cm}$ of the bone bridge intact between two tunnels over the tibia (-Fig. 1a). Next, the K-wires were pulled out and replaced by 14 gauge I.V. cannula needles loaded with looped 1-0 Polydioxanone (PDS, Ethicon, Johnson \& Johnson, New Jersey) sutures in medial and lateral tibial tunnels (-Figs. 1b and 1c). Once the tip of the cannula needle was visualized inside the joint on either side of the crater, the PDS suture loop was pushed upwards. The folded suture opens up as a loop because of the springy nature of the folded PDS. The cannula needles were left in the tunnel (-Fig. 2A). Now fracture was reduced using ACL tibial guide, and temporary percutaneous fixation of the fracture was performed using a $1.5 \mathrm{~mm}$ (K) wire (-Fig. 2B). Next, an 18 gauge I.V. cannula needle loaded with no. 1-0 PDS was inserted from far medial side entering into the joint parallel to the medial femoral condyle and above the medial meniscus. The tip of the needle was advanced into the medial loop and was then pierced into the ACL at the junction of the avulsed bone and ACL, a bit posteriorly (-Fig. $\mathbf{2 C}$ ). Once the needle tip was visualized on the lateral side of ACL, the PDS

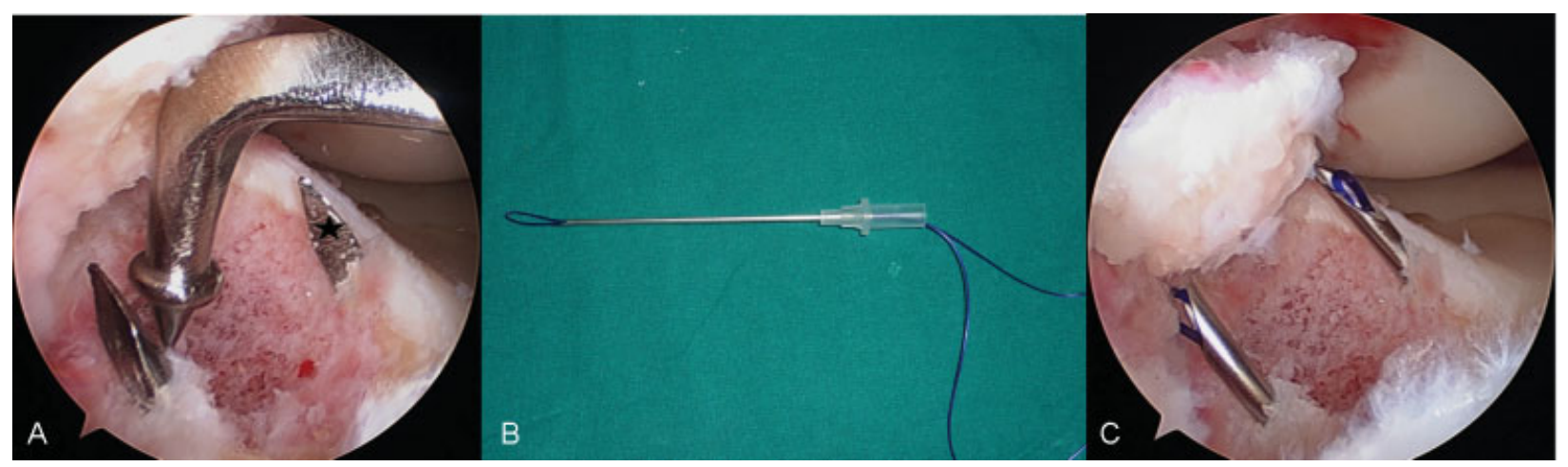

Fig. 1 (A) Arthroscopic image of right knee with two K-wires at the medial (black star) and lateral side of avulsion crater with ACL tip aimer adjacent to lateral wire. (B) Image of an I.V. cannula needle loaded with looped PDS. (C) K-wires replaced by I.V. cannula needles. ACL, anterior cruciate ligament; I.V., intravenous. 


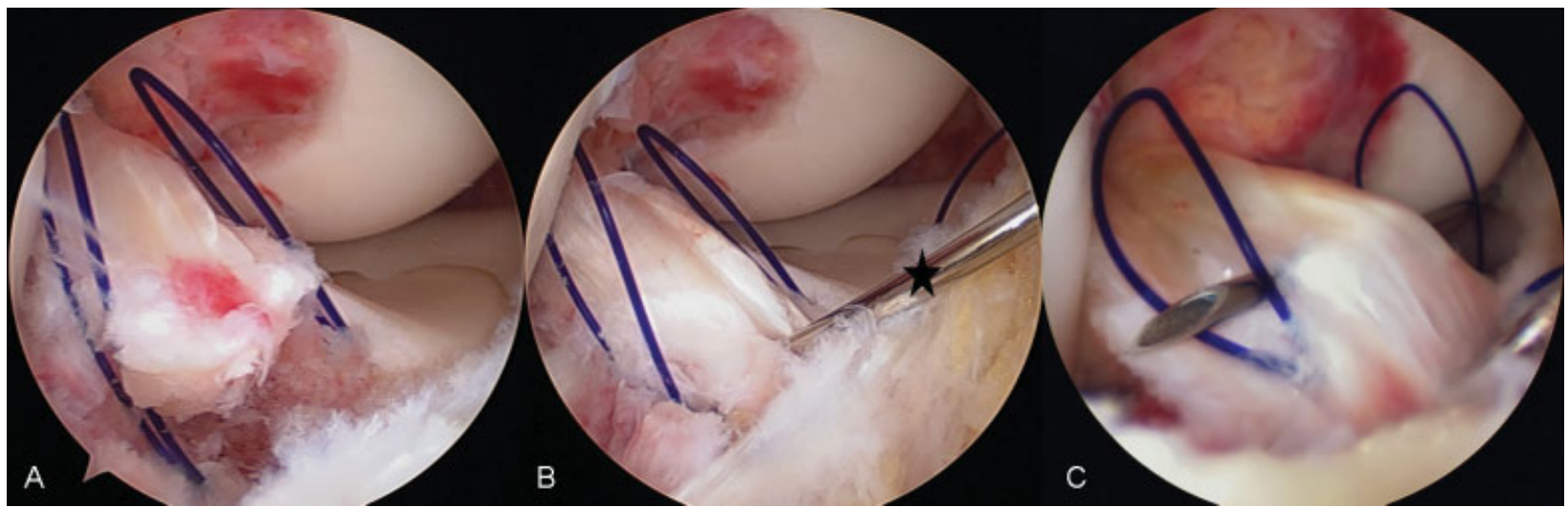

Fig. 2 (A) An arthroscopic image of PDS suture pushed through I.V. needle open up inside the joint. (B) Temporary reduction of fracture with percutaneous K-wire (black star). (C) Far medial side needle penetrating ACL ligament-bone junction and going through both loops of PDS suture. $\mathrm{ACL}$, anterior cruciate ligament; I.V., intravenous.

suture was advanced through the lateral PDS loop. The advanced end of the PDS was pulled out of the joint via AM portal using arthroscopic grasper (-Figs. 3 and $\mathbf{4 A}$ ). Frequently, the suture grasper was used to pull the PDS out of the lateral loop in a case where it did not enter into the lateral loop. Similar step was repeated by taking a bite through the anterior third of ACL substance, and PDS pulled out via AM portal.

Next, the two PDS sutures were replaced by ULTRABRAID (Smith \& Nephew, Andover, MA) by the shuttling technique (-Fig. 4B). Then, the needle and PDS loops were pulled out of the tunnel, which further pulls the ULTRABRAID sutures out of the joint through the tibial tunnels. ULTRABRAID sutures were tied one by one over the bone bridge or suture button (Smith \& Nephew, Andover, MA) keeping the knee in 30-degree flexion. The K-wire used for a temporary reduction was removed, and ACL probed for adequate tension (-Fig. 4C). Finally, the knee was

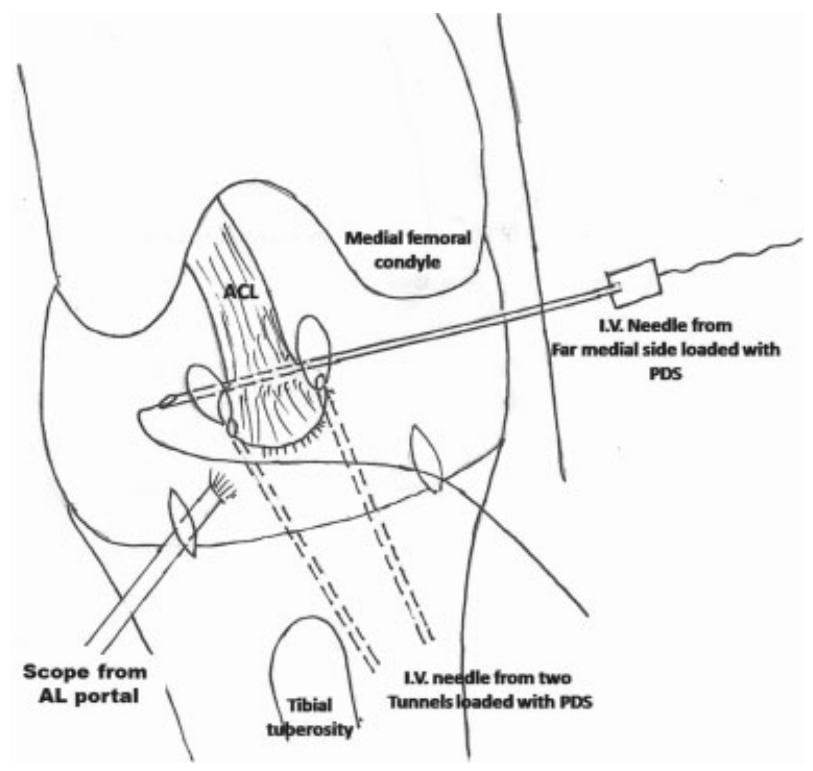

Fig. 3 Illustrated diagram of the technique. completely extended to check for intercondylar notch roof impingement with the fixed avulsed tibial spine. Furthermore, surgical incisions were closed in layers.

\section{Rehabilitation}

Postoperatively, the knee was immobilized in an extension brace for 2 weeks for all age groups, and patients were allowed nonweight bearing ambulation with axillary crutches. Gradual knee mobilization was encouraged 3rd week onwards. Partial weight bearing was allowed after 6 weeks and full weight bearing was allowed after complete fracture union.

\section{Review Protocol}

Clinical evaluation was done by an independent observer at $3,6,12$, and 24 months and then yearly. Patients' assessment involved asking for residual complaints, range of movement (ROM) assessment, manual instability test (Lachman and Pivot Shift test), KT-1000 arthrometer (MEDMetric, San Diego, CA) assessment, and Lysholm and IKDC scoring. An independent radiologist did a radiological assessment of the fracture union. For the assessment of growth disturbance following fixation of ACL avulsion with transphyseal tunnels in case of skeletally immature patients (with open physis), the alignment of the limb was assessed clinically in sagittal and coronal planes and limb length of index side was compared with non-index side with standard clinical method after squaring the pelvis. No hip-knee-ankle standing radiograph was used to assess the deformity or limb length discrepancy.

\section{Statistical Analysis}

All statistical analysis was performed using IBM SPSS Statistics software (version 16.0; IBM, Armonk, NY). Frequency was used to determine the descriptive statistics for categorical variable (sex, side of injury, and Meyer and McKeever type of fracture), whereas descriptive statistics were used to describe the continuous variables (age, follow-up months, IKDC and Lysholm scores, and KT-1000 readings). Independent sample $t$-test was used to compare various groups and functional scores. 


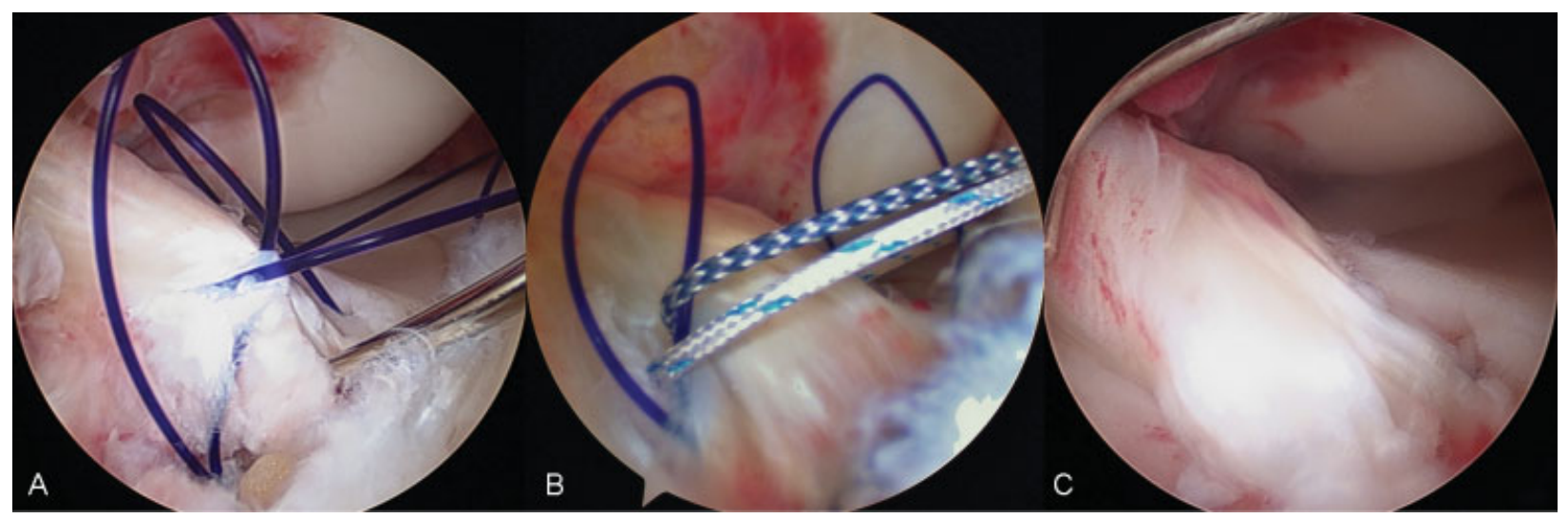

Fig. 4 (A) An arthroscopic image of PDS pulled out through anteromedial portal. (B) Replaced PDS suture by ULTRABRAID (Smith and Nephew, Andover) and Orthocord (Johnson and Johnson, New Brunswick, NJ). (C) Reduced avulsion fracture in crater.

\section{Results}

A total of 26 patients with a mean age of 24.5 years (range, 12-47 years) were included. Right knee was involved in 14 patients (53.8\%) and left knee in 12 patients (46.2\%). The mean time interval between the injury and surgery was 6.7 days. Twenty-three patients $(88.5 \%)$ were male and 3 (11.5\%) were female. Twelve patients (46.2\%) had Meyer and McKeever type III avulsion fracture and 14 patients (53.8\%) had type IV. - Table 1 describes the demographic and injury details of all patients. Seventeen (65.4\%) out of 26 patients had intermeniscal ligament entrapment. All fractures showed union at the follow-up period of 12 weeks. The mean follow-up period was 31 months (range, 24-60 months). At the final follow-up, mean ( \pm standard deviation [SD]) postoperative Lysholm score and subjective IKDC score were $97.7( \pm 3.62$; range, $89-100)$ and 95.5 ( \pm 4.21 ; range, $82.8-100)$, respectively. All patients had IKDC objective score A except one who was graded as IKDC grade $B$.

Mean $( \pm$ SD) side-to-side difference for anterior translation of the tibia measured with KT-1000 was $0.85( \pm 0.9$; range, $0-4.5 \mathrm{~mm}$ ). All patients, irrespective of their laxity status confirmed by KT-1000 measurement, had no instability and demonstrated hard end point on Lachman test with negative pivot shift at final follow-up. There was statistically significant difference between the Lysholm scores of open versus closed physes group (99.6 vs. 96.5, $p<0.03$ ) (-Table 2). However, there was no statistically significant difference in IKDC scores (subjective and objective) and KT-1000 measurements between the various groups (open vs. closed physes group and Meyer and McKeever type III vs. IV) (-Tables 2, 3). ROM analysis at final follow-up revealed that no patient had flexion or extension deficit. Two patients had to undergo arthroscopic adhesiolysis at the 4-month postoperative period as they failed to regain full ROM despite aggressive physiotherapy (an adult with loss of 40-degree flexion and the other, a 12year-old boy, with loss of 10-degree extension).

\section{Associated Injuries}

Five patients (19.2\%) had one or more ligamentous injuries that were managed appropriately ( - Table $\mathbf{1}$ ). A patient with medial collateral ligament (MCL) avulsion had grade zero valgus laxity with the knee in 0 and 30-degree flexion at final follow-up. Another two patients (7.7\%) had associated fractures of the medial malleolus and fracture of talus neck with medial malleolus, respectively. They underwent operative fixation of fractures. Their ankles were normal at final follow-up.

\section{Complications Other than Stiffness}

Six out of eight patients in whom tibial pull-out sutures were tied over suture button had pain over the button site. All six were given a trial of conservative treatment with nonsteroidal antiinflammatory drugs. Four patients responded to conservative treatment, while two required removal of the button as conservative treatment failed in them. No patient had wound-related infection, intra-articular infection, or deep vein thrombosis.

\section{Discussion}

The most significant finding of our study which concurs with the available literature is that suture pull-out fixation of displaced ACL avulsion from tibia utilizing I.V. cannula needle gives excellent results in all age groups (skeletally immature and mature) without any significant complications. The mean subjective IKDC and Lysholm scores reported in our series in all age groups and all types of fractures (McKeever type III and IV) were similar to the ones reported by other authors who used suture pull-out technique to fix ACL bony avulsion, suggesting that arthroscopic suture fixation provides excellent clinical outcome after ACL bony avulsion., 15-19,22 Though Berg et al had raised concern about clinical failure of arthroscopic fixation, ${ }^{23}$ we did not find any instance of fixation failure even in comminuted fractures.

Although variety of implants (screws, staples, wires, anchors, and sutures) have been used for arthroscopic fixation of tibial spine, but currently arthroscopic suture pull-out 
32 Arthroscopic Fixation of Displaced Tibial Spine Avulsion Fracture Pandey et al.

Table 1 Demographic and injury data of patient population

\begin{tabular}{|c|c|c|c|c|}
\hline ID & $\begin{array}{l}\text { Age }(y) \text {, sex, } \\
\text { index side }\end{array}$ & $\begin{array}{l}\text { Meyers and } \\
\text { McKeever's } \\
\text { classification }\end{array}$ & Mode of trauma & Associated intra-articular/extra-articular injury \\
\hline 1 & $27, M, R$ & IV & Fall from motorbike & Nil \\
\hline 2 & $28, M, L$ & IV & Fall from motorbike & Partial damage to $\mathrm{ACL}$ \\
\hline 3 & $41, M, L$ & IV & $\begin{array}{l}\text { Motorbike skid: } \\
\text { bike fell over knee }\end{array}$ & Nil \\
\hline 4 & $28, \mathrm{M}, \mathrm{L}$ & IV & $\begin{array}{l}\text { Motorbike skid: } \\
\text { landed over knee }\end{array}$ & Nil \\
\hline 5 & $14, \mathrm{M}, \mathrm{L}$ & III & Fall from cycle & Nil \\
\hline 6 & $19, \mathrm{M}, \mathrm{R}$ & IV & $\begin{array}{l}\text { Motor cycle pillion rider, } \\
\text { direct injury to knee }\end{array}$ & $\begin{array}{l}\text { Lateral meniscus posterior third longitudinal tear: } \\
\text { Repaired }\end{array}$ \\
\hline 7 & $30, M, R$ & IV & Fall from motorbike & Nil \\
\hline 8 & $14, M, L$ & IV & Fall on ground while playing & Nil \\
\hline 9 & $41, M, L$ & III & Fall from motorbike & Nil \\
\hline 10 & $22, F, R$ & III & Fall from motorbike & Nil \\
\hline 11 & $14, \mathrm{M}, \mathrm{R}$ & III & $\begin{array}{l}\text { Fall from cycle after leg } \\
\text { got stuck in wheel }\end{array}$ & Nil \\
\hline 12 & $12, \mathrm{M}, \mathrm{R}$ & III & Fall from cycle & Nil \\
\hline 13 & $31, M, R$ & III & $\begin{array}{l}\text { Fall from motorbike: } \\
\text { direct injury to knee }\end{array}$ & Ipsilateral transverse medial malleolus \#: fracture fixed \\
\hline 14 & $33, \mathrm{M}, \mathrm{R}$ & IV & $\begin{array}{l}\text { Fall from motorbike: } \\
\text { direct injury to knee }\end{array}$ & Nil \\
\hline 15 & $47, M, R$ & III & $\begin{array}{l}\text { Fall from motorbike: } \\
\text { twisted knee }\end{array}$ & Nil \\
\hline 16 & $28, M, L$ & IV & $\begin{array}{l}\text { Fall from motorbike: } \\
\text { bike fell on knee }\end{array}$ & $\begin{array}{l}\text { Lateral meniscus posterior third longitudinal tear: } \\
\text { repaired }\end{array}$ \\
\hline 17 & $21, M, R$ & III & Fall from motorbike & Nil \\
\hline 18 & $26, M, R$ & IV & Fall from motorbike & Nil \\
\hline 19 & 14, M, L & IV & Hit by school bench & $\begin{array}{l}\text { Oblique small tear in posterior third of medial meniscus: } \\
\text { partial meniscectomy }\end{array}$ \\
\hline 20 & $13, M, L$ & III & Fall while playing & Nil \\
\hline 21 & $16, F, L$ & IV & Fall from motorbike & $\begin{array}{l}\text { Associated talus \#, medial malleolus \# and ankle } \\
\text { subluxation: reduction and fixation }\end{array}$ \\
\hline 22 & $13, \mathrm{M}, \mathrm{L}$ & III & Fall from cycle & Nil \\
\hline 23 & $14, \mathrm{M}, \mathrm{R}$ & III & Fall while playing & Nil \\
\hline 24 & $39, F, R$ & III & Direct hit by motorbike & MCL avulsion from tibia side: repaired \\
\hline 25 & $38, M, L$ & IV & Fall from motorbike & Nil \\
\hline 26 & $14, \mathrm{M}, \mathrm{R}$ & III & Fall from cycle & Nil \\
\hline
\end{tabular}

Abbreviations: ACL; anterior cruciate ligament; F, female; M, male; MCL, medial collateral ligament; R, right; L, left; \#, fracture.

fixation seems to be the most preferred fixation method in all age groups. ${ }^{15,18,19,22,24}$ Many biomechanical cadaveric studies prove that suture pull-out fixation method seems to possess superior fixation properties over other methods. ${ }^{25-27}$ However, few authors claim that suture fixation method has a higher chance of failure. ${ }^{28,29}$ Nevertheless, with many excellent clinical outcome reports in last decade, currently arthroscopic suture fixation of tibial spine seems to be a preferred method of rigid fixation enabling early knee mobilization, suited for fixation of comminuted fractures, MRI compatibil- ity, and most importantly it obviates the need for implant removal later. ${ }^{13,15}$

However, standard ligament suture method requires special instruments, such as penetrator, Caspari Punch (Arthrex, Naples, Florida), or suture lasso. Also, mostly these instruments are available with shoulder surgeons and an exclusive knee surgeon may not have access to such instruments. Furthermore, while penetrating ACL, these wide bore instruments can damage the ACL substance, especially if the bite has to be repeated. This may be of concern in cases where ACL 
Table 2 Statistical analysis between adolescent and adult groups comparing Lysholm score, IKDC score, and KT-1000 arthrometer measurement

\begin{tabular}{|l|l|l|l|}
\hline & $\begin{array}{l}\text { Mean Lysholm } \\
\text { score }\end{array}$ & $\begin{array}{l}\text { Mean IKDC } \\
\text { subjective score }\end{array}$ & $\begin{array}{l}\text { Mean KT-1000 arthrometer } \\
\text { Side to side difference (in mm) }\end{array}$ \\
\hline Open physis group $(N=10)$ & 99.6 & 96.7 & 0.5 \\
\hline Closed physis group $(N=16)$ & 96.5 & 94.8 & 1.0 \\
\hline$p$-value & 0.03 & 0.3 (ns) & 0.18 (ns) \\
\hline
\end{tabular}

Abbreviations: IKDC, International Documentation Knee Committee; mm, millimeter; ns, not significant.

Note: $p>0.05$ except between Lysholm score of adolescent versus adult $(p<0.05)$.

Table 3 Statistical analysis between Type III and IV fracture comparing Lysholm score, IKDC score, and KT-1000 arthrometer measurement

\begin{tabular}{|l|l|l|l|}
\hline $\begin{array}{l}\text { Meyer and McKeever } \\
\text { type }\end{array}$ & $\begin{array}{l}\text { Mean Lysholm } \\
\text { score }\end{array}$ & $\begin{array}{l}\text { Mean IKDC } \\
\text { score }\end{array}$ & $\begin{array}{l}\text { Mean KT-1000 arthrometer } \\
\text { Side to side difference (in mm) }\end{array}$ \\
\hline Type 3 $(N=12)$ & 98.8 & 96.9 & 1.1 \\
\hline Type 4 $(N=14)$ & 96.7 & 94.3 & 0.6 \\
\hline$p$-value & $0.14(n s)$ & $0.11(n s)$ & 0.1 (ns) \\
\hline
\end{tabular}

Abbreviations: IKDC, International Knee Documentation Committee; mm, millimeter; ns, not significant.

substance is partially damaged, which was the situation in our case 2 (-Table 1 ). The I.V. cannula needle used in all our cases is readily available in all operating rooms. The diameter of the 18 gauge I.V. cannula needle is quite narrow to damage the ACL substance even if the bite has to be repeated. It is also easy to take a bite from medial to the lateral side of ACL in a straight line, and it does not require the use of complex maneuver inside the knee joint. Also, a similar needle although larger diameter (14 gauge) was used as suture retriever from the tibial tunnels obviating the need of having specialized Hewson suture retriever. Hsu et al utilized steel needle with nylon loop in the tibial tunnel to pull out sutures, but used penetrator to take a bite. ${ }^{30}$ Furthermore, this technique can also be safely employed in patients with open physis as the diameter of the two tibial tunnels is only $1.8 \mathrm{~mm}$ each, which is less than 7 to $10 \%$ of the growth plate size. Several authors have determined that a physeal lesion of size less than 7 to $10 \%$ of the physeal diameter is not likely to cause growth changes. ${ }^{31,32}$

\section{Male:Females}

Majority of the patients reported in our series were males (23 cases; 88.5\%). Koukoulias et al had a similar trend of more males than females $(3: 1){ }^{7}$ whereas Huang et al reported more females and fewer males (1.58:1). ${ }^{15}$ However, we believe that this factor may have no clinical relevance.

\section{Age and Mechanism of Injury}

ACL avulsion is more common in children than adults (3:2) because of the relative unossified state of the tibial eminence and the highly elastic nature of ACL. ${ }^{2,33}$ However, many studies have documented a higher incidence in adults too, ${ }^{16,22}$ and many authors have published their series in an exclusive adult population only. ${ }^{7,15,34}$ In our study, the child adult ratio was $1: 1.6$, indicating a higher involvement of adults. The reason attributed to this reversal of the ratio is increasing number of motor vehicle accidents involving adults. We did not find any difference in patients who had open physes and closed physes with respect to IKDC and KT-1000 displacements. However, the difference between the Lysholm scores of two groups (open vs. closed physes) was statistically significant (99.6 vs. 96.5). Hunter et al too reported a better outcome in patients less than 16 years of age. ${ }^{16}$

\section{Associated Injuries}

There can be associated injuries to menisci, cartilage, capsule, and MCL in up to $59 \%$ of the patients in children and adolescent age group.,35,36 Meniscal tear is the most frequently associated intraarticular pathology along with tibial spine avulsion. ${ }^{7,22,34}$ The overall incidence of associated ligament injury in our series was $19.2 \%(n=5)$, with $11.5 \%$ $(n=3)$ having meniscal injury. Two patients had ankle injuries. Mean Lysholm (96.66) and IKDC scores (94.85) of these 7 patients were not different from the other 19 (Lysholm, 98.1; IKDC, 95.91) $(p>0.05)$.

\section{Intermeniscal Ligament Entrapment}

The reported incidence of intermeniscal ligament entrapment between crater and avulsed spine is up to $67 \%$. The entrapped intermeniscal ligament is similar to Stener lesion of thumb, and blocks reduction of tibial spine as well as impairs healing of avulsed fragment to the crater. Hence, retraction or partial resection is necessary to be tailored according to the case. ${ }^{7,16,22}$ We encountered $65.4 \%$ of the patients $(n=17)$ with entrapment of the transverse intermeniscal ligament, which is quite similar to the one reported 
in literature. Though Ahn et al recommended complete excision of the intermeniscal ligament, as it may block reduction, we did not resect it in any of our cases as reduction could be achieved by retracting it using a probe or traction suture. Also, intermeniscal ligament is hypothesized to stabilize the anterior horns of two menisci. Hence, its preservation should be attempted. ${ }^{37}$

\section{Postoperative Laxity}

The postoperative laxity is attributed to an initial stretch of ACL before giving away at the tibial attachment site, ${ }^{38}$ unrecognized intra-substance tears, and improper anatomical reduction. ${ }^{39}$ Even though literature reports suggest increased postoperative laxity up to $6 \mathrm{~mm}$ in 10 to $20 \%$ of the patients treated with tibial spine fixation, ${ }^{7,18,40-42}$ we did not find such increased laxity tendency in our patients. Only one patient had $4.5 \mathrm{~mm}$ laxity on KT-1000 measurement, whereas the rest had laxity between 0 and $1.3 \mathrm{~mm}$ (side-to-side difference) without any instability. Further, we did not find any difference in laxity between the open versus closed physis group. Mere presence of laxity may not amount to instability because of integrity of nerve fibers in ACL and intact neuromuscular feedback. ${ }^{41}$

\section{Complications}

Postoperative stiffness of the knee is the most common complication observed in many series, and is because of arthrofibrosis or mechanical impingement of displaced bony fragment. ${ }^{34,39,43,44}$ However, recently many authors report minimal incidence of arthrofibrosis after arthroscopic rigid fixation and early mobilization within 2 to 4 weeks, indicating that early mobilization can reduce the rate of arthrofibrosis and improve the outcome. ${ }^{15-18,41}$ In our study, only two patients $(7.7 \%)$ had postoperative knee stiffness who recovered completely after arthroscopic adhesiolysis. One patient, who was 12-year-old, had 10-degree extension deficit. It was because of an enlarged bump of the tibial spine that was shaved off during arthroscopy. Baxter et al reported that the enlargement of the tibial spine was probably because of increased blood supply after injury. ${ }^{45}$ The other patient had 40-degree flexion loss, who recovered completely after arthroscopic adhesiolysis. We believe that unlike traditional ACL reconstruction that is performed after a few weeks to let the inflammation subside; in avulsion injuries, surgery is performed on an inflamed knee followed by immobilization that may lead to stiffness. However, early mobilization after rigid fixation can minimize the incidence of arthrofibrosis.

Also, we did not find any growth disturbance or deformity in our series of patients with open physis unlike Ahn et al who reported two cases: one of limb length discrepancy and the other of genu recurvatum following the pull-out suture technique. $^{22}$

\section{Follow-Up}

The mean follow-up period in our study was 31 months (range, 24-60 months). Few authors followed-up for a longer timeframe from 80 to 91 months. ${ }^{15,22}$ We consider the followup period in our study sufficient for both clinical and radio- logical follow-ups because even patients with postoperative stiffness returned to normalcy by 6 months from the index procedure. The uneventful patients achieved their final stability, ROM, and radiological union by 3 to 6 months itself and maintained an almost same postoperative state since then. However, we also believe that longer follow-up periods of 5 to 15 years may be required to study several changes: one, to notice any growth disturbances in patients with open physis and two, to notice the arthritic changes in patients with closed physis, if any, happening in the joint especially in those patients who remained a bit lax as compared with no laxity ones after fixation. Does this laxity could cause a subtle change in the biomechanics of the knee leading to degenerative change? This will be interesting to study in the long term.

The major limitation of our study is the lack of comparative group in terms of conservative treatment offered and different type of fixation, which could have helped in deciding the best fixation option. Also, a longer follow-up period in patients with open physis of 5 to 6 years or up to the skeletal maturity would have definitely confirmed the safety of this procedure in terms of damage to the growth plate, if any.

\section{Conclusion}

Arthroscopic reduction and fixation of the avulsed tibial spine using high strength nonabsorbable sutures using I.V. cannula needle as penetrator and suture retriever is a simple and reproducible technique, which gives excellent clinical outcome in all age groups with any significant complications.

\section{Conflict of Interest}

None.

Acknowledgment

None.

\section{References}

1 Kendall NS, Hsu SY, Chan KM. Fracture of the tibial spine in adults and children. A review of 31 cases. J Bone Joint Surg Br 1992;74(6): 848-852

2 Meyers MH, McKeever FM. Fracture of the intercondylar eminence of the tibia. J Bone Joint Surg Am 1959;41-A(2):209-222

3 Zaricznyj B. Avulsion fracture of the tibial eminence: treatment by open reduction and pinning. J Bone Joint Surg Am 1977;59(8): 1111-1114

4 Panni AS, Milano G, Tartarone M, Fabbriciani C. Arthroscopic treatment of malunited and nonunited avulsion fractures of the anterior tibial spine. Arthroscopy 1998;14(3):233-240

5 Sullivan DJ, Dines DM, Hershon SJ, Rose HA. Natural history of a type III fracture of the intercondylar eminence of the tibia in an adult. A case report. Am J Sports Med 1989;17(1):132-133

6 Shelbourne KD, Urch SE, Freeman H. Outcomes after arthroscopic excision of the bony prominence in the treatment of tibial spine avulsion fractures. Arthroscopy 2011;27(6):784-791

7 Koukoulias NE, Germanou E, Lola D, Papavasiliou AV, Papastergiou SG. Clinical outcome of arthroscopic suture fixation for tibial eminence fractures in adults. Arthroscopy 2012;28(10): $1472-1480$ 
8 Furlan D, Pogorelić Z, Biocić M, Jurić I, Mestrović J. Pediatric tibial eminence fractures: arthroscopic treatment using K-wire. Scand J Surg 2010;99(1):38-44

9 Doral MN, Atay OA, Leblebicioğlu G, Tetik O. Arthroscopic fixation of the fractures of the intercondylar eminence via transquadricipital tendinous portal. Knee Surg Sports Traumatol Arthrosc 2001; 9(6):346-349

10 Wiegand N, Naumov I, Vámhidy L, Nöt LG. Arthroscopic treatment of tibial spine fracture in children with a cannulated Herbert screw. Knee 2014;21(2):481-485

11 Kobayashi S, Terayama K. Arthroscopic reduction and fixation of a completely displaced fracture of the intercondylar eminence of the tibia. Arthroscopy 1994;10(2):231-235

12 Oohashi Y. A simple technique for arthroscopic suture fixation of displaced fracture of the intercondylar eminence of the tibia using folded surgical steels. Arthroscopy 2001;17(9):1007-1011

13 Vega JR, Irribarra LA, Baar AK, Iñiguez M, Salgado M, Gana N. Arthroscopic fixation of displaced tibial eminence fractures: a new growth plate-sparing method. Arthroscopy 2008;24(11): $1239-1243$

14 Wouters DB, de Graaf JS, Hemmer PH, Burgerhof JG, Kramer WL. The arthroscopic treatment of displaced tibial spine fractures in children and adolescents using Meniscus Arrows ${ }^{\circledR}$. Knee Surg Sports Traumatol Arthrosc 2011;19(5):736-739

15 Huang TW, Hsu KY, Cheng CY, et al. Arthroscopic suture fixation of tibial eminence avulsion fractures. Arthroscopy 2008;24(11): 1232-1238

16 Hunter RE, Willis JA. Arthroscopic fixation of avulsion fractures of the tibial eminence: technique and outcome. Arthroscopy 2004; 20(2):113-121

17 May JH, Levy BA, Guse D, Shah J, Stuart MJ, Dahm DL. ACL tibial spine avulsion: mid-term outcomes and rehabilitation. Orthopedics 2011;34(2):89

18 Tudisco C, Giovarruscio R, Febo A, Savarese E, Bisicchia S. Intercondylar eminence avulsion fracture in children: long-term follow-up of 14 cases at the end of skeletal growth. J Pediatr Orthop B 2010;19(5):403-408

19 Wagih AM. Arthroscopic treatment of avulsed tibial spine fractures using a transosseous sutures technique. Acta Orthop Belg 2015;81(1):141-146

20 Gans I, Babatunde OM, Ganley TJ. Hybrid fixation of tibial eminence fractures in skeletally immature patients. Arthrosc Tech 2013;2(3):e237-e242

21 Accousti WK, Willis RB. Tibial eminence fractures. Orthop Clin North Am 2003;34(3):365-375

22 Ahn JH, Yoo JC. Clinical outcome of arthroscopic reduction and suture for displaced acute and chronic tibial spine fractures. Knee Surg Sports Traumatol Arthrosc 2005;13(2):116-121

23 Berg EE. Comminuted tibial eminence anterior cruciate ligament avulsion fractures: failure of arthroscopic treatment. Arthroscopy 1993;9(4):446-450

24 Coyle C, Jagernauth S, Ramachandran M. Tibial eminence fractures in the paediatric population: a systematic review. J Child Orthop 2014;8(2):149-159

25 Anderson CN, Nyman JS, McCullough KA, et al. Biomechanical evaluation of physeal-sparing fixation methods in tibial eminence fractures. Am J Sports Med 2013;41(7):1586-1594

26 Bong MR, Romero A, Kubiak E, et al. Suture versus screw fixation of displaced tibial eminence fractures: a biomechanical comparison. Arthroscopy 2005;21(10):1172-1176
27 Eggers AK, Becker C, Weimann A, et al. Biomechanical evaluation of different fixation methods for tibial eminence fractures. Am J Sports Med 2007;35(3):404-410

28 Hapa O, Barber FA, Süner G, et al. Biomechanical comparison of tibial eminence fracture fixation with high-strength suture, EndoButton, and suture anchor. Arthroscopy 2012;28(5):681-687

29 Sawyer GA, Anderson BC, Paller D, Schiller J, Eberson CP, Hulstyn M. Biomechanical analysis of suture bridge fixation for tibial eminence fractures. Arthroscopy 2012;28(10):1533-1539

30 Hsu SY. An easy and effective method for reattaching an anterior cruciate ligament avulsion fracture from the tibial eminence. Arthroscopy 2004;20(1):96-100

31 Janarv PM, Wikström B, Hirsch G. The influence of transphyseal drilling and tendon grafting on bone growth: an experimental study in the rabbit. J Pediatr Orthop 1998;18(2):149-154

32 Stadelmaier DM, Arnoczky SP, Dodds J, Ross H. The effect of drilling and soft tissue grafting across open growth plates. A histologic study. Am J Sports Med 1995;23(4):431-435

33 Meyers MH, McKeever FM. Fracture of the intercondylar eminence of the tibia. J Bone Joint Surg Am 1970;52(8):1677-1684

34 Delcogliano A, Chiossi S, Caporaso A, Menghi A, Rinonapoli G. Tibial intercondylar eminence fractures in adults: arthroscopic treatment. Knee Surg Sports Traumatol Arthrosc 2003;11(4): 255-259

35 Lafrance RM, Giordano B, Goldblatt J, Voloshin I, Maloney M. Pediatric tibial eminence fractures: evaluation and management. J Am Acad Orthop Surg 2010;18(7):395-405

36 Mitchell JJ, Sjostrom R, Mansour AA, et al. Incidence of Meniscal Injury and Chondral Pathology in Anterior Tibial Spine Fractures of Children. J Pediatr Orthop 2015;35(2):130-135

37 Muhle C, Thompson WO, Sciulli R, et al. Transverse ligament and its effect on meniscal motion. Correlation of kinematic MR imaging and anatomic sections. Invest Radiol 1999;34(9):558-565

38 Kogan MG, Marks P, Amendola A. Technique for arthroscopic suture fixation of displaced tibial intercondylar eminence fractures. Arthroscopy 1997;13(3):301-306

39 Montgomery KD, Cavanaugh J, Cohen S, Wickiewicz TL, Warren RF, Blevens F. Motion complications after arthroscopic repair of anterior cruciate ligament avulsion fractures in the adult. Arthroscopy 2002;18(2):171-176

40 Kocher MS, Foreman ES, Micheli LJ. Laxity and functional outcome after arthroscopic reduction and internal fixation of displaced tibial spine fractures in children. Arthroscopy 2003;19(10): 1085-1090

41 Perugia D, Basiglini L, Vadalà A, Ferretti A. Clinical and radiological results of arthroscopically treated tibial spine fractures in childhood. Int Orthop 2009;33(1):243-248

42 Sharma A, Lakshmanan P, Peehal J, David H. An analysis of different types of surgical fixation for avulsion fractures of the anterior tibial spine. Acta Orthop Belg 2008;74(1):90-97

43 Patel NM, Park MJ, Sampson NR, Ganley TJ. Tibial eminence fractures in children: earlier posttreatment mobilization results in improved outcomes. J Pediatr Orthop 2012;32(2):139-144

44 Vander Have KL, Ganley TJ, Kocher MS, Price CT, Herrera-Soto JA. Arthrofibrosis after surgical fixation of tibial eminence fractures in children and adolescents. Am J Sports Med 2010;38(2): 298-301

45 Baxter MP, Wiley JJ. Fractures of the tibial spine in children. An evaluation of knee stability. J Bone Joint Surg $\mathrm{Br}$ 1988;70(2): $228-230$ 